\title{
Mitigation of Correlated Risk in Construction Projects
}

\author{
Jarosław Konior \\ Department of Construction Methods and Management, Faculty of Civil Engineering, Wroclaw University of Science and Technology, \\ Poland
}

Copyright $(2019$ by authors, all rights reserved. Authors agree that this article remains permanently open access under the terms of the Creative Commons Attribution License 4.0 International License

\begin{abstract}
The purpose of this article is to present the preparation of Project Risk Assessment Methodology and its mitigation. The main text provides a summary of the approach, the method used and the findings. The conclusions have been drawn that the proper tools for quantifying risks have to be based on the criteria specific for mathematical statistic and probability or at least fuzziness. Function, which makes possible to categorize any risks into one of the five categories, is combination of probability and impact to one of the items: people and their safety or budget and cost or schedule and planning or quality and performance. An attempt was made to express numerically the relationship between risks impacts and their level of likelihood. Also, the method was presented of associating the influence of projects risks impacts on the extent of the likelihood of project risk occurrence which makes possible to determine the direction and the strength of this relationship. Point bi-serial coefficient between project risks impacts and risks occurrence makes possible to determine the direction and the strength of this relationship. Measured risks may be foreseen before they strongly impact on construction projects. The construction high and critical risks to be mitigated are the following: project schedule, cost budget, design technical issues and safety at construction sites.
\end{abstract}

Keywords Project, Management, Construction, Mitigation, Correlation, Risk

\section{Introduction}

\section{Decision Making Process and Risks}

Project risk is defined as an unplanned event or condition that, if occurs, has a negative effect on a Project Objective. Risk management stands for identification, assessment, and prioritization of risks defined in ISO 31000 followed by coordinated and economical application of resources to minimize, monitor, and control the probability and / or impact of unfortunate events or to maximize the realization of opportunities. Several risk management standards have been developed in construction management companies for years, enhanced by implementation ISO 9001 standard [2], [12], [14], [16].

While estimating risks in construction projects, experts face problems of working on the qualitative (immeasurable data) basis rather than on a quantitative one. The decision making theory presents a classical split of such situations that have been presented from three following points of view [8]:

- Degree of uncertainties;

- Number of experts;

- Number of decision making phases.

In the axis 'level of uncertainty' in Figure 1, the following decisions pertaining to uncertain and fuzzy situations have been marked:

- certainties: the entire information describing the decision making process has deterministic character, which means that possibilities of decision choice are precisely known; decision making in such a case is limited to maximizing of the usefulness function in the value analysis;

- risk: the entire information describing the decision making process is probabilistic, i.e. probability distributions are easily applied; the decision making process stands for optimization of the expected value of usefulness function;

- uncertainties: even the probability distributions are unknown; the decision making relies on application of min-max strategy to ensure the best possible value of usefulness in the worst expected conditions;

- fuzzy state: uncertainties tackle not only the existence of an event appearance but its overall meaning that cannot be described by probabilistic methods. 


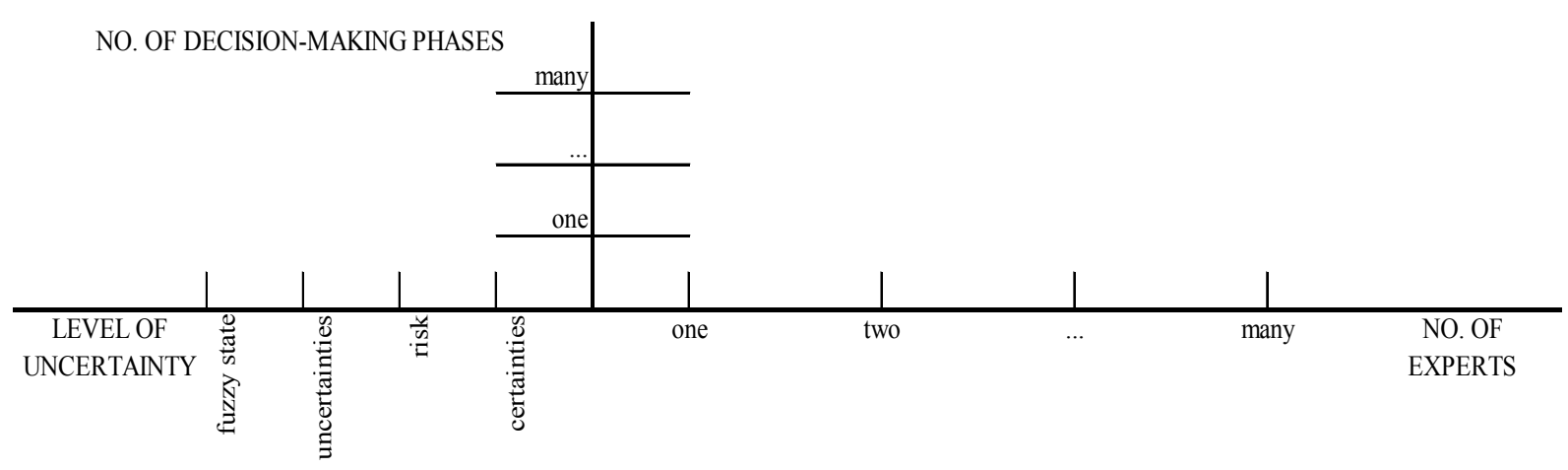

Figure 1. Classification scheme of decision making tasks in conditions of uncertainty

Some other combinations are possible, e.g. by adding risk to uncertainties.

In the axis 'number of experts' the following situations have been shown: one decision maker, two, and many. If there are more than one decision maker than they may be representative of more groups or organisations that cannot be treated as a uniform group because their interests may stay in conflict with one another by representing different points of view.

In the axis 'number of decision making phases' there are two fundamental situations: one phase and many phases. They reflect the problem in both aspects - static and dynamic.

By combining these groups of situations shown in three axes in Fig. 1 all possible states of making decision have been elaborated, e.g.: 'certainties - one decision expert one phase of decision making process', 'risk - two experts - many decision phases', 'uncertainties - two experts - one decision phase', etc. These combinations cover all areas of decision making theories, e.g.: two-player games, N-player games, multiphase decision making process, etc. Unfortunately, not all of these states of making decisions are fully described by mathematical models and confirmed by practical applications. It is generally said that the further the experts go along the axis the less recognized the states of making decision process are [1], [8], [15].

\section{Principles and Scopes of the Risk Review}

A risk has a cause and, if it occurs, an impact. A project risk is an unplanned event or condition that, if it occurs, has a negative effect on a project objective. The following project objectives were considered when completing this risk assessment [6]:

- Safety;

- Cost;

- Schedule;

- Quality and Performance.

The risk assessment was structured around the following topics [2], [3], [7], [9], [16]:

\section{Method of Risk Identification}

The method applied to identify and assess "high level" project risks was as follows [2], [3], [5], [6], [10], [16]:

- Identify a potential risk;

- $\quad$ Categorise the expected impact on the project using the definitions provided in Table 1 as a guideline;

- Categorise the likelihood of the risk occurring using the definitions provided in Table 2 as a guideline;

- Combine the impact and likelihood to determine the risk using the matrix provided in Table 3;

- Identify a risk reduction strategy for each risk, using the principles outlined in Table 4;

- Identify actions as appropriate;

- At follow-up meetings, determine the status of the identified actions;

- Re-categorise the impact and likelihood on the basis of the action taken. This is called the "residual risk".

Tables 2, 3, 4 below represent a 5x5 risk matrix approach which represents standard project management approach and should be amended as appropriate - figure 2 . Alternatives may be used to suit a project or customer. Where an alternative to a $5 \times 5$ matrix is used, e.g. a $3 \times 3$ matrix, $3 \times 2$ matrix, customer specific matrix, etc. 
Table 1. Project Risk Assessment Topics

\begin{tabular}{|c|c|c|}
\hline No. & Main Topic & Sub-Topic \\
\hline 1. & Project Scope & Scope Definition, Basis of Design, Future Requirements, Public Relations \\
\hline 2. & Project Objectives & Defined Objectives \\
\hline 3. & Project Organisation & $\begin{array}{l}\text { Project Team, Roles and Responsibilities, Communications, Continuity Interface with } \\
\text { Operations }\end{array}$ \\
\hline 4. & $\begin{array}{l}\text { Confidentiality } \\
\text { Information Security }\end{array}$ & Confidentiality, Information Security \\
\hline 5. & Project Schedule & $\begin{array}{l}\text { Overall Schedule, Third Party Deliverables, Project Team, Decision Making, Detailed } \\
\text { Design, Procurement, Construction, Commissioning, Qualification }\end{array}$ \\
\hline 6. & $\begin{array}{l}\text { Cost } \\
\text { Budget }\end{array}$ & $\begin{array}{l}\text { Funding Approval, Control Budget, Design Development, Value Management, } \\
\text { Contingency, Change Control }\end{array}$ \\
\hline 7. & $\begin{array}{l}\text { Contracts } \\
\text { Procurement Strategy }\end{array}$ & $\begin{array}{l}\text { Contract Strategy, Procurement Strategy, Insurance, Shipping, Transportation } \\
\text { Requirements, Critical Equipment }\end{array}$ \\
\hline 8. & External Threats Risks & External Threats, Organisational Weaknesses \\
\hline 9. & Project Quality Performance & Quality Strategy, Customer Requirements, Product Contamination \\
\hline 10. & $\begin{array}{l}\text { Third Party } \\
\text { Regulatory \& Approvals }\end{array}$ & $\begin{array}{l}\text { Planning Conditions, Planning Objections, Fire Certification, Building Regulations, } \\
\text { Permitting Requirements Regulatory, Insurers Requirements }\end{array}$ \\
\hline 11. & $\begin{array}{l}\text { Design } \\
\text { Technical Issues }\end{array}$ & $\begin{array}{l}\text { New Technology, Process Design, Process Equipment, Process Utilities, Automation, IS, } \\
\text { Instrumentation, Electrical, IT, Building Services, Fire Engineering, Civil, Structural, } \\
\text { Architectural, Piping, Security Systems, Environmental Monitoring, WWTP and } \\
\text { Environmental Designs, Design Co-Ordination, Specifications and Standards }\end{array}$ \\
\hline 12. & Safety & $\begin{array}{l}\text { Safety Management Systems, Operator Safety, Contractor Safety, Safe access/egress, } \\
\text { ATEX, Construction Regulations }\end{array}$ \\
\hline 13. & Environmental Issues & Waste Management Strategy, Noise, Emissions \\
\hline 14. & Technology Transfer & Technology and Knowledge Transfer \\
\hline 15. & Operational Issues & Operational Issues, Spare Parts Strategy, Vendor Strategy \\
\hline 16. & $\begin{array}{l}\text { Construction and Interfaces } \\
\text { Operations }\end{array}$ & $\begin{array}{l}\text { Construction Safety, Construction Interfaces with Operations } \\
\text { Construction Interfaces with Other Projects IR Issues }\end{array}$ \\
\hline 17. & $\begin{array}{l}\text { Commissioning } \\
\text { Qualification }\end{array}$ & Commissioning, Phased Commissioning, Availability of Utilities, Qualification Strategy \\
\hline 18. & Facilities Logistics & Offices, Space Allocation, IT Support, Document Management \\
\hline
\end{tabular}

Table 2. Impact categories and descriptions

\begin{tabular}{|c|c|c|c|c|c|}
\hline Impact & Category & People & $\begin{array}{c}\text { Cost } \\
\text { (example) }\end{array}$ & Schedule & Quality \\
\hline 1 & $\begin{array}{l}\text { Very } \\
\text { Low }\end{array}$ & Slight Injury & $<€ 50 \mathrm{~K}$ & $<1$ week & Minor impact on operation of facility \\
\hline 2 & Low & First Aid & $\begin{array}{l}€ 50 \mathrm{~K}- \\
€ 200 \mathrm{~K}\end{array}$ & $1-2$ weeks & Affecting operation of a non-critical item of equipment \\
\hline 3 & Medium & $\begin{array}{l}\text { Minor Injury, Restricted } \\
\text { Workday Case }\end{array}$ & $\begin{array}{l}€ 200 \mathrm{~K}- \\
€ 1 \mathrm{M}\end{array}$ & 3-8 weeks & Affecting operation of a critical item of equipment \\
\hline 4 & High & $\begin{array}{l}\text { Major Injury, Lost Time } \\
\text { Injury }\end{array}$ & $€ 1 \mathrm{M}-€ 10 \mathrm{M}$ & $\begin{array}{c}2-4 \\
\text { months }\end{array}$ & Affecting operation of a production unit/area \\
\hline 5 & Critical & $\begin{array}{l}\text { Total Disability, One or } \\
\text { More Fatality }\end{array}$ & $>€ 10 \mathrm{M}$ & $\begin{array}{c}>4 \\
\text { months }\end{array}$ & $\begin{array}{l}\text { Affecting operation of the overall facility or ability to } \\
\text { meet project user requirement specification }\end{array}$ \\
\hline
\end{tabular}

Table 3. Likelihood of occurrence categories and descriptions

\begin{tabular}{|c|c|c|c|}
\hline Likelihood & Category & \multicolumn{2}{|c|}{ Description } \\
\hline A & Very Low & Incident hardly occurs in industry & $<0.1 \%(1$ in 1000$)$ \\
\hline B & Low & Incident has occasionally occurred in industry & $<5 \%(1$ in 20$)$ \\
\hline C & Medium & Incident has occurred previously & $<100 \%$ \\
\hline D & High & Incident has occurred more than once & $100 \%$ \\
\hline E & Very High & Incident expected to occur & $<0$ \\
\hline
\end{tabular}


The above categorising risks against their impact and likelihood when appear determine 5 risk mitigation strategies [7], [12], [13]. During the risk review, each topic is considered in terms of its applicability to the proposed development and relevant comments are recorded. When required, actions are identified and recorded with responsibility assigned.

Table 4. Risk Mitigation Strategies

\begin{tabular}{|c|l|}
\hline Strategy & \multicolumn{1}{|c|}{ Description } \\
\hline Avoid it & $\begin{array}{l}\text { Where possible, risks should be eliminated or } \\
\text { avoided, e.g. through design change, procedure, etc. }\end{array}$ \\
\hline Reduce it & $\begin{array}{l}\text { Where it is not possible to eliminate the risk, every } \\
\text { effort should be made to minimise/reduce the risk. }\end{array}$ \\
\hline Monitor it & $\begin{array}{l}\text { In some instances, the most appropriate course of } \\
\text { action may be to monitor the situation and only take } \\
\text { action if required. }\end{array}$ \\
\hline Transfer it & $\begin{array}{l}\text { In some instances, risk can be transferred, e.g. } \\
\text { insurance cover. }\end{array}$ \\
\hline Accept it & $\begin{array}{l}\text { In some instances, the project team may be willing } \\
\text { to accept the risk. This is generally true only for } \\
\text { lower level risk items. }\end{array}$ \\
\hline
\end{tabular}

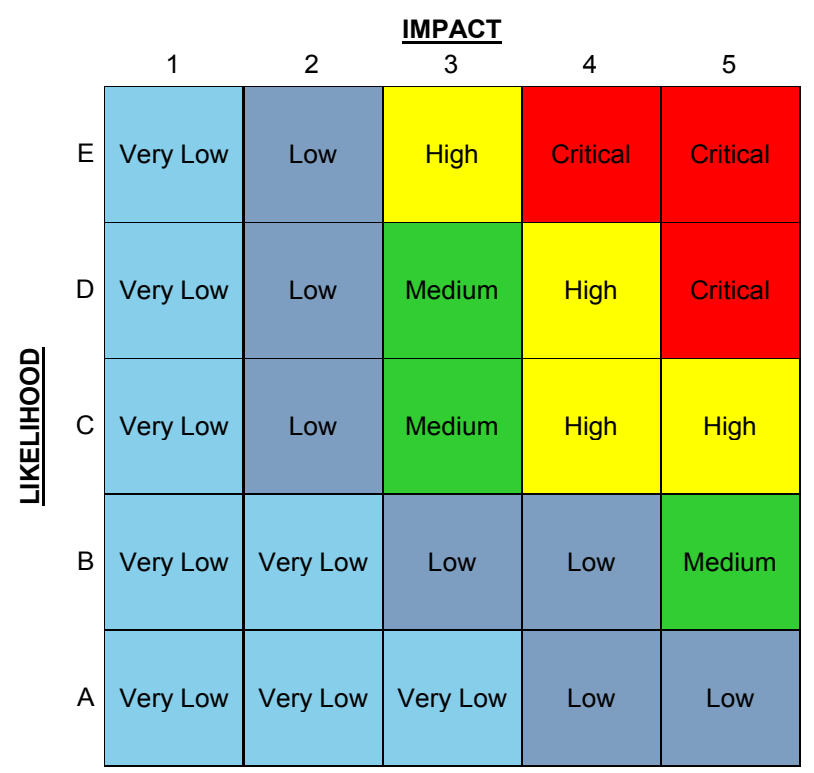

Figure 2. Risk Matrix

As noted previously, actions were identified during the risk assessment meetings. Actions should be completed by the persons noted as responsible or designated as appropriate. During the review meetings the status of the actions identified is reviewed and the risk re-categorised in each case bearing the action taken in mind. The revised risk is referred to as residual risk in the risk assessment record sheets. The expectation for residual risk is that it reduces as actions are completed or as the status of the project changes. In some instances, the risk may become no longer relevant (NLR). Typically, risks become no longer relevant if the possibility of the risk occurring has passed due to, for example, project progress. Risks are also categorised as no longer relevant if the risk consequence has been accepted by the team [4].

\section{Status of Risks Identified}

The status of the risks identified during the risk assessment meetings is summarised below. Please note that N/A refers to items which were noted for information only and where a categorisation of risk was not appropriate. NLR refers to items that are no longer relevant [4].

These are graphically shown on the risk matrix in Figure 3. Due to the format of this diagram, some of the bars are hidden, i.e. low bars hidden behind higher bars, however, the number of issues associated with each bar is indicated on the chart, including the hidden bars [7], [9].

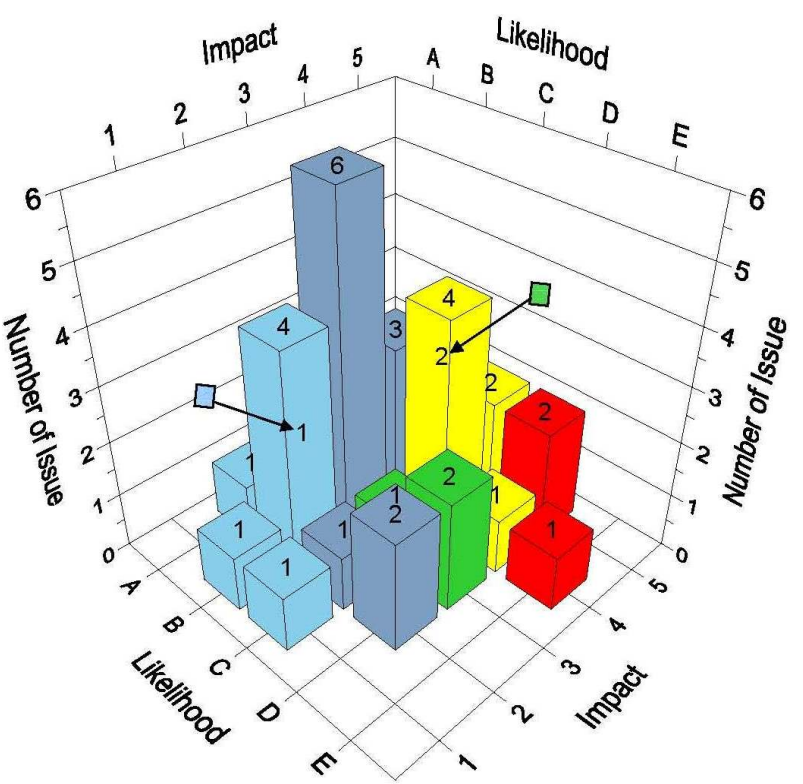

Figure 3. Number of Issues by impact and likelihood

\section{Association of Risks Impacts Occurrence with Their Likelihood}

An assessment of the risk impact and its likelihood occurrence relies on identification of two types of variables [11], [12]:

- Non-measurable - qualitative variables, i.e. individual project risks impacts $\mathrm{i}_{\mathrm{ij}}$;

- Measurable - quantitative variables, i.e. likelihood of individual project risk occurrence $l_{\mathrm{i}}$.

After the types of variables li and $i_{i j}$ have been defined, an attempt was made at the numerical expression of relationship (should such relationships exist) between them, i.e. an attempt at measuring the influence of projects risks impacts on the extent of the likelihood of project risk occurrence. In the calculation of the strength of this relationship, the method of determination of the point bi-serial correlation coefficient (generally marked as $\mathrm{r}(\mathrm{L})$ ) for the measurable property $l_{i}$ and the dichotomous property $i_{i j}$, was used. This is one of a few cases in the statistics when properties of various types are being 
correlated. The coefficient of correlation value falls within an interval $[-1,1]$. In the sets of impacts $\mathrm{I}$ for each elementary impact $\mathrm{i}_{\mathrm{ij}}=\mathrm{ii}$ (when $\mathrm{j}=1,2, \ldots, \mathrm{m}$ ) and the likelihood of project risks $\mathrm{L}$, the following was determined:

- $\mathrm{i}_{\mathrm{i}}$ - dichotomous variable that takes on values $0\left(\mathrm{i}_{\mathrm{i}} 0\right)$ or $1\left(i_{i} 1\right) ; i=1,2, \ldots, n$;

- $\quad \mathrm{i} 0$ - number of observations of the variable $\mathrm{i}_{\mathrm{i}}$ marked as 0 ;

- $\quad \mathrm{i} 1$ - number of observations of the variable $\mathrm{i}_{\mathrm{i}}$ marked as 1 ;

apparently $\mathrm{i}=\mathrm{i}_{0}+\mathrm{i}_{1}$ (if by $\mathrm{i}$, one shall understand the number of all observations $i_{i}$ ), and:

- $\quad l_{i}$ - measurable variable; values of this variable were divided into two groups distinguished on this basis: whether $l_{j}$ takes values 0 or $1 ; i=1,2, \ldots, n$;

- $\quad \mathrm{li} 0$ - value of the property $\mathrm{l}_{\mathrm{i}}$ for these units ,i”, for which the property $i_{i 0}$ occurs;

- $\quad$ li1 - value of the property $l_{i}$ for these units ,„i”, for which them property $i_{i 1}$ occurs.

Next, arithmetic averages were calculated in the both groups:

$$
\begin{aligned}
& \overline{l_{0}}=\frac{1}{i_{0}} \sum_{i=1}^{i_{0}} l_{i 0} \\
& \overline{l_{1}}=\frac{1}{i_{1}} \sum_{i=1}^{i_{1}} l_{i 1}
\end{aligned}
$$

the standard deviation (determined for the correlation $\mathrm{r}(\mathrm{l})$ with a relationship defined in a different way):

$$
d(L)=\sqrt{\frac{i \sum_{i=1}^{i} l_{i}^{2}-\left(\sum_{i=1}^{i} l_{i}\right)^{2}}{i(i-1)}}
$$

and as a result, on the basis of (1-3), the point Bi-serial correlation coefficient $\mathrm{r}(\mathrm{l})$ :

$$
r(l)=\frac{\overline{l_{1}}-\overline{l_{0}}}{d(L)} \sqrt{\frac{i_{1} i_{0}}{i(i-1)}}
$$

The above presented method of associating the influence of projects risks impacts on the extent of the likelihood of project risk occurrence makes possible to determine the direction and the strength of this relationship shown in figure 3 .

\section{Indicative Research and First Conclusion}

There were 19 similar projects - industrial green field plants, approximately 10.000 square meters area each, with around $40 \mathrm{mln}$ pln budget - selected, investigated and researched to describe relation between project risks impacts and likelihood of project risks occurrence [9], [11]. The point bi-serial correlation coefficients $r(1)$ have been determined to measure reason-effect relationship 'risks impacts - likelihood of risks occurrence' on the basis these projects analysis. The results of $\mathrm{r}(\mathrm{l})$ chosen coefficients have been presented in the table 5 .

Due to lack of entire information while reporting of the investigated projects and not sufficient number of them only 8 topics of risks assessment that occurred have been associated with the projects risks impacts [7], [9]. The point bi-serial correlation coefficients $r(l)$ have been determined for all of them and represent interesting conclusions from indicative research - table 5:

- the direction of the relationship is right-hand (positive) for all 8 risks assessed and occurred but the strength of correlation between project risks impacts and likelihood of project risks occurrence shows a considerable span (from 0.18 to 0.95 );

- the unanimous trend of bi-serial correlation coefficients $\mathrm{r}(\mathrm{l})$ growth has been observed - the higher / more serious project risk impact, the bigger value of $\mathrm{r}(\mathrm{l})$ is;

- the trend of $\mathrm{r}(\mathrm{l})$ is more significant and the values of coefficients are exceeding 0.5 for projects risks which are more measurable and easier to quantify then

\begin{tabular}{|c|c|c|c|c|c|c|}
\hline \multirow{2}{*}{ No. } & \multirow{2}{*}{ Risks Assessment Topics Occurred } & \multicolumn{5}{|c|}{ r(1) for Risks Impacts by Categories } \\
\hline & & Very Low & Low & Medium & High & Critical \\
\hline 1. & Project Scope & 0.18 & 0.21 & 0.29 & 0.32 & 0.34 \\
\hline 5. & Project Schedule & 0.26 & 0.29 & 0.39 & 0.58 & 0.71 \\
\hline 6. & Cost Budget & 0.29 & 0.35 & 0.46 & 0.68 & 0.88 \\
\hline 9. & Project Quality Performance & 0.16 & 0.20 & 0.26 & 0.31 & 0.35 \\
\hline 11. & Design Technical Issues & 0.28 & 0.31 & 0.42 & 0.52 & 0.73 \\
\hline 12. & Safety & 0.32 & 0.40 & 0.51 & 0.69 & 0.95 \\
\hline 13. & Environmental Issues & 0.15 & 0.19 & 0.22 & 0.31 & 0.33 \\
\hline 16. & Construction and Interfaces Operations & 0.20 & 0.23 & 0.32 & 0.39 & 0.46 \\
\hline
\end{tabular}
others: project schedule, cost budget, design technical issues and safety constrains

Table 5. Point Bi-serial Coefficients between Project Risks Impacts and Risks Occurrence 


\section{Discussion on Construction Risks Mitigation}

Point bi-serial coefficients between project risks impacts and risks occurrence stands for the simplest method of associating the influence of projects risks impacts on the extent of the likelihood of project risk occurrence which makes possible to determine the direction and the strength of this relationship. Therefore, such approach indicates measured risks to be foreseen mitigated before they strongly impact on construction projects. The construction high and critical risks to be mitigated are the following: project schedule, cost budget, design technical issues and safety at construction sites.

Although the presented approach of projects risks assessment by linking risks impacts with their likelihood occurrence is quite well described in accessible literature [2], [3], [4], [6], [10], [13], [14], [16] but there is not sufficient number of construction projects reported and tested in measurable way. The data of enterprises in construction industry are under confidentiality agreements and well protected by global clients, project management companies and credit bank analysts. To make thing worse some of projects risks may or may not occur, therefore their nature is moved to fuzzy sets categories rather than belonging to probabilistic area where models of likelihood risks impacts may be determined easily. However, the approach, the research and the conclusions presented in the article - even indicative ones - are worth further investigations and exploring. This will make more possible pinpoint, determine, monitor and mitigate the most impactful risk appearing in construction projects.

\section{REFERENCES}

[1] Abdul-Rahman H., Wang Ch., Y. L. "Design and pilot run of fuzzy synthetic model (FSM) for risk evaluation in civil engineering", Journal of Civil Engineering and Management, 2013, pp. 217-238.

[2] Almeida N. M., Sousa V., Dias L. A., Branco F., "Engineering risk management in performance-based building environments", Journal of Civil Engineering and Management 2015, pp. 218-230.
[3] Almeida N. M., Sousa V., Dias L. A., Branco F., "Managing the technical risk of performance-based building structures", Journal of Civil Engineering and Management 2015, pp. 384-394.

[4] Akintoye, A. S., Malcolm J., "Risk analysis and management in construction", International Journal of Project Management, 1997, 15.1, pp. 31-38.

[5] Chi S., Han S., Kim D. Y., Shin Y. "Accident risk identification and its impact analyses for strategic construction safety management", Journal of Civil Engineering and Management 2015,pp. 524-538.

[6] Edwards, P. J.; Bowen, P. A., "Risk and risk management in construction: a review and future directions for research", Engineering, Construction and Architectural Management, 1998, 5.4, pp. 339-349

[7] "Quality Management System", PM Group, Ireland, 2003-2015

[8] Kacprzyk J., "Fuzzy sets in systematic analysis", PWN, Warsaw 1986, pp. 25-28, 67-72

[9] Konior J., "Risk management in PM Group Polska", Project Management Group procedures, Wroclaw 2014

[10] Mak, S.; Picken, D., "Using risk analysis to determine construction project contingencies", Journal of Construction Engineering and Management, 2000, 126.2: 130-136.

[11] Morrison D. F., "Multivariate statistical methods", McGraw - Hill Book Company, New York 1990, pp. 121-123

[12] Silvestre J. D., Silva A., de Brito J., "Uncertainty modelling of service life and environmental performance to reduce risk in building design decisions", Journal of Civil Engineering and Management 2015, pp. 308-322

[13] Smith, N. J.; Merna, T.; Jobling P., "Managing risk in construction projects", Wiley-Blackwell, 2009, pp. 16-19

[14] Ward, S. C.; Chapman, C. B., "Risk management perspective on the project lifecycle", International Journal of Project Management, 1995, 13.3, pp. 145-149.

[15] Yu J., Jeon M., Kim T. W., "Fuzzy-based composite indicator development methodology for evaluating overall project performance", Journal of Civil Engineering and Management 2015, pp. 343-355.

[16] Zavadskas E.K, , Turskisb Z., Tamošaitienec J., "Risk assessment of construction projects", Journal of Civil Engineering and Management 2010, pp. 33-46. 